\title{
ANALISIS USAHA DAN NILAI TAMBAH AGROINDUSTRI KERUPUK SINGKONG
}

\author{
Haryati La Kamisi \\ Staf Pengajar FAPERTA UMMU-Ternate, e-mail: ilman_haq23@yahoo.com
}

\begin{abstract}
ABSTRAK
Agroindustri kerupuk singkong menggunakan bahan utama singkong. Kerupuk singkong banyak diproduksi oleh industri rumah tangga (Home Industri). Pada industri rumah tangga ini pengunaan tenaga kerjanya melibatkan tenaga kerja dari dalam maupun luar keluarga untuk melakukan aktivitas produksi.

Penulis berkeinginan melakukan analisis usaha dan nilai tambah kerupuk singkong dengan perumusan masalah mengenai : (1) bagaimana sistem pengolahan kerupuk singkong, (2) berapa besar nilai usaha (biaya, penererimaan, dan pendapatan) pada kerupuk singkong, (3) berapa besar nilai tambah (biaya, penererimaan, dan pendapatan) pada kerupuk singkong. Tujuan penelitian ini untuk mencari jawaban dari perumusan masalah tersebut.

Berdasar hasil penelitian dapat disimpulkan sebagai berikut : (1) dalam sekali produksi, biaya total home industry kerupuk singkong sebesar Rp 4.626.995,-, penerimaan total home industry kerupuk singkong sebesar $R p$ 9.243.000,-, keuntungan total home industry kerupuk singkong sebesar Rp. 4.616.005,-. (3) Produksi kerupuk singkong mampu memberikan nilai tambah sebesar $R p 4.044,2 / k g$ dengan rasio nilai tambah $0.61 \%$ dari nilai produksi.
\end{abstract}

\section{Kata Kunci: Penerimaan, Keuntungan, Nilai Tambah}

\section{PENDAHULUAN}

\subsection{Latar belakang}

Sektor pertanian dalam wawasan agribisnis dengan perannya dalam perekonomian nasional memberikan beberapa hal yang menunjukkan keunggulan yang patut dipertimbangkan dalam pembangunan nasional. Keunggulan tersebut antara lain melihat tingginya nilai tambah agroindustri. Dengan kontribusi tersebut dalam perekonomian nasional maka sektor agribisnis semakin dipacu mengenai pengembangan teknologi yang ada.

Pengembangan teknologi tersebut karena masih ada yang salah yang dihadapi oleh agroindustri yaitu antara lain: (1), penyediaan bahan baku yang teratur dalam bentuk kuantitas maupun kualitas yang memadai, serta harga bersaing yang masih menjadi persoalan pelik bagi agroindustri. Apalagi bahan baku tersebut harus dibeli di pasar bebas dari petani kecil yang lokasinya berpencar-pencar. (2), pemasaran karena produk yang dihasilkan mempunyai kualitas yang kurang baik, sering sangat sulit memasarkan produk-produk dengan kemasan dan label yang menarik. (3), pengangkutan produk agroindustri cenderung mahal karena soal jarak yang jauh.

Dengan demikian pengembangan agroindustri berlokasi di daerah sentra produksi atau di daerah produksi bahan baku itu sendiri perlu menjadi perhatian. Karena pengembangan agroindustri ada keterkaitan dengan tujuan pembangunan wilayah pedesaaan dan keterlibatan sumber daya manusia pedesaan. Sehingga dapat memperkenalkan tambahan kegiatan atau perlakuan terhadap komoditi setelah dipanen yang nantinya dapat memperoleh nilai tambah dari komoditi yan dihasilkan.

Potensi singkong untuk dijadikan komoditas tidak boleh dianggap remeh. Bagi pengembangan usaha budidaya singkong sangat terbuka sebab beragan jenis industri memanfaatkan singkong sebagai bahan baku. Kurang lebih 14 macam turunan dibuat dari produk olahan berbahan dasar singkong, baik gablek, chips, pellet, maupun tepung tapioka.

Kebutuhan pasar dalam negeri misalnya pada industri makanan dan minuman (keripik, sirup), industri tekstil, industri bahan bangunan (gips, keramik), industri kertas, serta industri 
pakan ternak. Sedangkan peluang ekspor dengan tujuan negara-negara ekspor Masyarakat Ekonomi Eropa, Jepang, Korea, China, Amerika Serikat, digunakan sebagai bahan baku farmasi, bahan baku industri lem, bahan baku industri kertas, bahan baku industri pakan ternak, atau malah sebagai bahan baku BBM alternatif biofuel.

\subsection{Perumusan Masalah}

Beberapa permasalahan yang ingin diteliti dalam penelitian ini, antara lain:

1. Bagaimana proses pengolahan kerupuk singkong?

2. Bagaimana besar nilai usaha (biaya, penerimaan, pendapatan dan $\mathrm{R} / \mathrm{C}$ rasio)

pada kerupuk singkong?

3. Berapa besar nilai tambah pada kerupuk singkong?

\subsection{Tujuan Penelitian}

Tujuan yang akan dilakukan adalah sebagai berikut:

1. Mengetahui proses pengolahan kerupuk singkong yang telah diterapkan.

2. Mengetahui nilai usaha (biaya, penerimaan, pendapatan dan R/C rasio) padakerupuk singkong.

3. Mengetahui nilai tambah pada kerupuk singkong.

\subsection{Kegunaan Penelitian}

Hasil penelitian ini diharapkan dapat berguna:

1. Bagi pihak industri kerupuk singkong pada khususnya diharapkan dapat membuka wawasan dan memberikan gambaran usahanya dalam pengambilan keputusan.

2. Sebagai sumber informasi bagi instansi sipil dan swasta yang berkepentingan.

3. Sebagai bahan perbandingan dan rujukan bagi peneliti selanjutnya atau peneliti serupa.

\section{METODE PENELITIAN}

\subsection{Jenis dan Sumber Data}

Jenis data yang dikumpulkan meliputi data primer dan data sekunder.Data primer didapat dengan menggunakan metode wawancara langsung pada responden dengan daftar pertanyaan yang sudah disiapkan. Adapun data primer yang diambil dalam penelitian ini adalah data-data biaya, penerimaan dan pendapatan pengolahan kerupuk singkong serta profil atau latar belakang usaha.
Data sekunder adalah data atau informasi yang berasal dari dokumentasi desa, perpustakaan, literatur yang relavan, dan instansiinstansi seperti Balai atau Kantor Dinas serta hasil-hasil penelitian terdahulu yang berhubungan dengan topik akan yang di teliti.

\subsection{Metode Penelitian}

Penelitian dilaksanakan di Kec. Kkota Ternate Tengah, Prov. Maluku Utara dengan metode kuantitatif, yaitu mendiskripsikan hasil dengan menggunakan Analisis Biaya dan Analisis Nilai Tambah. Dengan kedua analisis tersebut untuk menentukan keputusan industri pengolahan kerupuk singkong.

\subsection{Metode Analisis Data}

Dengan data yang sudah dikumpulkan sesuai dengan perumusan dan tujuan penelitian, kemudian melakukan pengecekan terhadap sifat data tersebut

dengan mentabulasi data. Data yang diperoleh dari hasil penelitian diolah dan dianalisis dengan menggunakan metode sebagai berikut:

\subsubsection{Analisis Biaya}

Analisis biaya digunakan untuk mengetahui besarnya biaya produksi yang dikeluarkan oleh produsen kerupuk singkong dan untuk mengetahui total biaya yang dikeluarkan. Secara sistematis dapat dihitung dengan memakai rumus:

$$
\mathrm{TC}=\mathrm{FC}+\mathrm{VC}
$$

Di mana:

$$
\begin{aligned}
\mathrm{TC}= & \text { Total Cost (Biaya Total, dinyatakan } \\
& \text { dalam Rp }) \\
\mathrm{FC}= & \text { Fixed Cost ( Biaya Tetap misal } \\
& \begin{array}{l}
\text { Penyusutan Peralatan, Sewa Lahan dan } \\
\text { Bangunan, dinyatakan dalam Rp ) }
\end{array} \\
\mathrm{VC}= & \text { Variabel Cost (Biaya Variabel/Biaya } \\
& \text { Tidak Tetap misal Bahan Baku, Tenaga } \\
& \text { Kerja, Listrik dab Bahan Bakar, } \\
& \text { dinyatakan dalam Rp) }
\end{aligned}
$$

\subsubsection{Analisis Penerimaan}

Analisis penerimaan digunakan untuk mengetahui besarnya penerimaan

yang diterima oleh produsen kerupuk singkong di Desa Mojorejo. Untuk mengetahui total penerimaan tersebut, secara matematik dapat dihitung dengan memakai rumus:

$\mathrm{TR}=\mathrm{P} \times \mathrm{Q}$ 
Dimana:

$$
\begin{aligned}
\mathrm{TR} & =\begin{array}{l}
\text { Total Revenue (Penerimaan } \\
\text { dinyatakan dalam Rp) }
\end{array} \\
\mathrm{P} & =\text { Price (Harga, dinyatakan dalam Rp) } \\
\mathrm{Q} & =\text { Quantity (Jumlah produksi) }
\end{aligned}
$$

\subsubsection{Analisis Pendapatan}

Analisis pendapatan digunakan untuk mengetahui besarnya pendapatan yang diterima oleh produsen kerupuk singkong. Untuk mengetahui total pendapatan tersebut, secara matematik dapat dihitung dengan memakai rumus:

$$
\pi=\mathrm{TR}-\mathrm{TC}
$$

\section{Dimana:}

$$
\begin{aligned}
\pi & =\text { Keuntungan/Pendapatan } \\
\mathrm{TR}= & \text { Total Revenue (Penerimaan Total, } \\
& \text { dinyatakan dalam Rp) } \\
\mathrm{TC}= & \text { Total Cost (Biaya Total, dinyatakan } \\
& \text { dalam Rp) }
\end{aligned}
$$

\subsubsection{Analisis Efiensi Usaha}

Untuk mengukur tingkat efisiensi usaha dalam proses produksi kerupuk singkong digunakan analisis $\mathrm{R} / \mathrm{C}$ rasio dengan rumus:

$$
\mathrm{R} / \mathrm{C} \text { ratio }=\mathrm{TR} / \mathrm{TC}
$$

Dimana:

TR = Total Revenue (Pennerimaan Total)

$\mathrm{TC}=$ Total Cost (Biaya Total)

Apabila hasil analisis :

$\mathrm{R} / \mathrm{C}$ rasio $>1$, maka usaha tersebutt efisien dan menguntungkan untuk diusahakan.

$\mathrm{R} / \mathrm{C}$ rasio $=1$, maka usaha tersebut tidak rugi dan tidak untung (impas).

$\mathrm{R} / \mathrm{C}$ rasio $<1$, maka usaha tersebut tidak efisien atau tidak menguntungkan untuk diusahakan.

\begin{tabular}{|c|c|c|}
\hline No & Variabel & Notasi \\
\hline 1. & Hasil Produksi (Kg/Hari) & a \\
\hline 2. & Bahan Baku (Kg/Hari) & b \\
\hline 3. & Tenaga Kerja (jam/Hari) & c \\
\hline 4. & Faktor Konversi (1/2) & $a / b=m$ \\
\hline 5. & Koefisien Tenaga Kerja (3/2) & $c / b=n$ \\
\hline 6. & Harga Produk Rata-Rata (Rp/Kg) & d \\
\hline 7. & Upah Rata-Rata (Rp/Jam) & e \\
\hline 8. & Harga Bahan Baku (Rp/Kg) & f \\
\hline 9. & Sumbangan Input Lain $(\mathrm{Rp} / \mathrm{Kg})^{*}$ & g \\
\hline 10. & Nilai Produksi (4x6) (Rp/Kg) & $m x d=k$ \\
\hline \multirow[t]{2}{*}{11.} & a. $\quad$ Nilai Tambah (10-9-8) $(\mathrm{Rp} / \mathrm{Kg})$ & $k-f-g=1$ \\
\hline & b. Ratio Nilai Tambah $(11 \mathrm{a} / 10)(\%)$ & $\mathrm{l} / \mathrm{k}=\mathrm{h}$ \\
\hline & a. Imbalan Tenaga Kerja $(5 \times 7)(\mathrm{Rp} / \mathrm{Kg})$ & $n x e=p$ \\
\hline & b. Bagian Tenaga Kerja (12a/11a) $(\%)$ & $p / l=q$ \\
\hline & a. Keuntungan $(11 a-12 a)^{* *}$ & $I-p=r$ \\
\hline & b. Tingkat Keuntungan (13a-11a) (\%) & $r / l=0$ \\
\hline
\end{tabular}

\subsubsection{Nilai Tambah}

Besarnya nilai tambah karena proses pengolahan didapat dari pengurangan biaya bahan baku ditambah input lainnya terhadap nilai produk yang dihasilkan. Nilai tambah merupakan imbalan bagi tenaga kerja dan keuntungan pengolah. Untuk menguji hipotesa bahwa pengolahan bahan baku memberikan nilai tambah yang dikemukan oleh Hayami ett.all, (1987).

\section{Tabel 3. Format Analisis Nilai Tambah}

Sumber: Sudiyono (2001)

*) Bahan Penolong

**) Imbalan bagi Pemodal dan Manajemen

Dasar perhitungan dari analisis nilai tambah ini adalah per kilogram hasil produksi. Standar harga bahan baku dan hasil produksi yang digunakan adalah standar harga di tingkat pengolah (produsen). Besarnya nilai tambah karena proses pengolahan adalah didapat dari pengurangan bahan baku dan input lainnya dari nilai produk yang dihasilkan, tidak termasuk tenaga kerja, dengan kata lain nilai tambah menggambarkan imbalan bagi tenaga kerja, modal dan manajemen yang dapat dinyatakan sebagai berikut:

$$
\text { Nilai Tambah }=\mathrm{f}(\mathrm{K}, \mathrm{B}, \mathrm{T}, \mathrm{U}, \mathrm{H}, \mathrm{h}, \mathrm{L})
$$

Keterangan:

$$
\begin{array}{ll}
\mathrm{K}: & \text { Kapasitas Produksi } \\
\mathrm{B}: & \text { Jumlah bahan baku yang digunakan } \\
\mathrm{T} & :
\end{array}
$$


$\mathrm{U}:$ Upah tenaga kerja

$\mathrm{H}$ : Harga Output

h : Harga Bahan Baku

L : Nilai input lain (nilai dari semua korbanan yang terjadi selama proses perlakuan untuk menambah nilai)

Dari hasil perhitungan tersebut akan dihasilkan keterangan sebagai berikut:

1. Perkiraan nilai tambah (dalam Rupiah)

2. Rasio nilai tambah terhadap nilai produk yang dihasilkan (dalam Persen)

3. Imbalan tenaga kerja (dalam Rupiah)

4. Imbalan bagi modal dan manajemen (dalam rupiah).

\subsection{Ruang Lingkup Penelitian}

Penelitian ini di fokuskan pada nilai tambah dan kelayakan usaha. Objek yang dikaji adalah produsen kerupuk singkong.

\section{HASIL DAN PEMBAHASAN \\ 3.1. Penerimaan}

Penerimaan merupakan jumlah produk yang dihasilkan dalam proses produksi dikalikan dengan harga jual produk. Tiap-tiap produsen kerupuk singkong mempunyai penerimaan yang berbeda-beda. Perbedaan ini disebabkan kapasitas produksi yang bervariasi.

Dengan harga jual yang berbeda-beda dari setiap responden antara $\mathrm{Rp} 5.500,-$ sampai dengan Rp 8.500,-, maka didapatkan harga jual rata-rata yang diperoleh dari tiap responden adalah $\mathrm{Rp}$ 6.400,-/kg. Penerimaan kerupuk singkong sebesar $\mathrm{Rp}$ 9.243.000,- dengan kapasitas hasil produksi sebanyak $1.516 \mathrm{~kg}$ dalam sekali produksi.

\subsection{Pendapatan / Keuntungan}

Pendapatan atau keuntungan yang akan didapat setelah mengetahui nilai biaya dan nilai penerimaan. Semua pemilik usaha kerupuk singkong memiliki pendapatan bernilai positif (untung). Total pendapatan pada usaha kerupuk singkong senilai Rp 4.616.005,- dalam sekali produksi untuk 5 pemilik usaha kerupuk singkong. Pendapatan terendah sampai terbesar dalam sekali produksi adalah Azis (Rp 73.541,-) dengan persentasi 1,6 \%, Nurul (Rp 382.142,-), Suliyat (Rp 430.779,-), Sholikin (Rp1.293.119,-), dan terakhir Edi Santoso ( $\operatorname{Rp} 2.436 .424,-)$ dengan persentasi tertinggi yaitu $52,8 \%$.

\subsection{R/C Ratio}

Analisis BC rasio digunakan untuk mengetahui tingkat efisiensi usaha pengolahan kerupuk singkong secara finansial. Efisiensi home industri bisa ditentukan dengan menghitung per cost ratio yaitu pembagian antara penerimaan suatu usaha dengan total biaya produksi.

Tabel 1.Total Penerimaan Dan Total Biaya Kerupuk Singkong Dalam Sekali Proses.

\begin{tabular}{clc}
\hline No. & \multicolumn{1}{c}{ Uraian } & Nilai (Rp) \\
\hline 1 & Total Penerimaan & $9.243 .000 .-$ \\
2 & Total Biaya & 4.626.995.- \\
\hline \multirow{2}{*}{ Sumber : Hasil Olahan Data Primer, 2010. }
\end{tabular}

Setelah mengetahui nilai penerimaan dan nilai biaya, maka dapat dihitung nilai $\mathrm{R} / \mathrm{C}$ rasio.

R/C Ratio = Rp 9.243.000,- / Rp 4.626..995,$=1,9976$ atau dapat diekuivalenkan $=2$

$\mathrm{R} / \mathrm{C}$ rasio pada kerupuk singkong sebesar 1,9976 atau 2 yang artinya $\mathrm{R} / \mathrm{C}$ rasio > 1 maka usaha tersebut efisien dan usaha ini menguntungkan. Nilai R/C rasio 1,9976 atau 2 berarti dengan mengeluarkan biaya sebesar 1 satuan maka akan menghasilkan penerimaan sebesar 1,9976 atau 2 satuan. Contoh jika mengeluarkan biaya sebesar Rp 100.000,- maka akan menghasilkan penerimaan sebesar Rp 199.760,- atau Rp 200.000,-.

\subsection{Analisis Nilai Tambah}

Dalam industri pengolahan hasil pertanian dapat menciptakan nilai tambah dan imbalan tenaga kerja. Tujuan analisis ini, untuk mengukur seberapa besar nilai tambah yang terdapat pada 1 (satu) kg kerupuk singkong. Hasil dari perolehan angka menunjukkan berapa dari 1 (satu) $\mathrm{kg}$ kerupuk singkong memberikan imbalan kerja bagi para pekerja. Jika nilai tambah tinggi, maka agroindustri akan lebih berperan dalam memberikan pendapatan pekerja. Sebagai dasar perhitungan nilai tambah adalah per kilogram bahan baku. Untuk lebih jelas, analisis nilai tambah kerupuk singkong dapat dilihat pada tabel.

Pada home industry kerupuk singkong terlihat bahwa dengan menggunakan bahan baku singkong sebanyak $2.050 \mathrm{~kg}$ dapat menghasilkan $1.516 \mathrm{~kg}$ kerupuk singkong. Usaha kerupuk singkong menggunakan tenaga kerja 23,2 HK/hari. Dengan demikian, koefisien tenaga kerja yang dibutuhkan untuk mengolah $2.050 \mathrm{~kg}$ singkong sebanyak 0.01 . Harga produk rata-rata Rp 6.400,-/kg dengan faktor konversi sebesar 0.74 . Hal ini dapat diartikan bahwa $1 \mathrm{~kg}$ singkong dapat menghasilkan kerupuk singkong 
sebesar $0.74 \mathrm{~kg}$. Dengan demikian, nilai produksi pada usaha kerupuk singkong ini sebesar $\mathrm{Rp}$ 4.732,9. Nilai produksi ini dapat dialokasikan untuk bahan baku singkong sebesar Rp 650,- dan sumbangan input lain (bahan bumbu kerupuk singkong) sebesar Rp 1210.1.

Besarnya nilai tambah dari produksi kerupuk singkong adalah Rp $2.782,8 / \mathrm{kg}$. Nilai ini diperoleh dari nilai produk pengurangan harga bahan baku dan sumbangan input lain. Jadi apabila membuat kerupuk singkong $100 \mathrm{~kg}$ bahan baku singkong maka akan memperoleh nilai tambah sebesar $\operatorname{Rp} 278.280$,- dengan rasio nilai tambah $61 \%$ dari nilai produksi.

Dari hasil pengolahan data penelitian ini diperoleh bahwa imbalan tenaga kerja $\mathrm{Rp}$ $370,6 / \mathrm{kg}$. Jadi artinya setiap pengggunaan bahan baku singkong $1 \mathrm{~kg}$ maka tenaga kerja mendapatkan imbalan sebesar Rp 370,6 atau 13\% dari nilai tambah. Sedangkan keuntungan yang diperoleh dari usaha kerupuk singkong adalah $\mathrm{Rp}$ $2.502,14 / \mathrm{kg}$ bahan baku dengan tingkat keuntungannya sebesar $87 \%$ dari nilai tambah pada usaha kerupuk singkong.

\section{KESIMPULAN}

Berdasarkan hasil penelitian yang dilakukan, analisis usaha dan analisis nilai tambah kerupuk singkong dapat disimpulkan bahwa :

1. Penerimaan total dari masing-masing produksi rumah tangga dalam sekali produksi sebagai berikut : Arman (Rp 360.000,-), Edi (Rp 4.158.000,-), Fatmah (Rp 900.000,-), Sholeh (Rp 2.040.000,-), dan Sulis (Rp 1.785.000,).

2. Keuntungan total dari masing-masing produksi rumah tangga dalam sekali produksi sebagai berikut : Arman ( $R p$ 73.541,-), Edi (Rp 2.436.424,-), Fatmah (Rp 382.142,-), Sholeh ( $\mathrm{Rp}$ 1.293.119,-), dan Sulis (Rp 430.779,-).

3. Nilai R/C rasio kerupuk singkong sebesar 1,9967 atau 2. Ini menandakan tingkat pengembalian investasi hampir atau mendekati $100 \%$.

4. Besarnya nilai tambah dari produksi kerupuk singkong adalah $\mathrm{Rp} 2.872,8 / \mathrm{kg}$ dengan rasio nilai tambah $61 \%$ dari nilai produksi . Jadi apabila membuat kerupuk singkong $100 \mathrm{~kg}$ bahan baku singkong maka akan memperoleh nilai tambah sebesar Rp 287.280,--

5. Imbalan tenaga kerja kerupuk singkong adalah sebesar $\mathrm{Rp} 370,63 / \mathrm{Kg}$ atau $13 \%$ dari nilai tambah, sedangkan imbalan keuntungan kepada pemilik usaha adalah sebesar Rp $2.502,14 / \mathrm{Kg}$ atau tingkat presentasenya sebesar $87 \%$ dari nilai tambah pada usaha kerupuk singkong.

Tabel 2. Analisis Nilai Tambah Kerupuk Singkong.

\begin{tabular}{|c|c|c|c|}
\hline No. & Variabel & Notasi & Nilai/Jumlah \\
\hline 1 & Hasil Produksi (kg/hari) & a & 1.516 \\
\hline 2 & Bahan Baku (kg/hari) & b & 2.050 \\
\hline 3 & Tenaga Kerja (HK/hari) & c & 23,2 \\
\hline 4 & Faktor Konversi & $a / b=m$ & 0,74 \\
\hline 5 & Koefisien Tenaga Kerja & $c / b=n$ & 0,01 \\
\hline 6 & Harga Produk rata-rata $(\mathrm{Rp} / \mathrm{kg})$ & d & 6.400 \\
\hline 7 & Upah rata-rata (Rp/hari kerja) & e & 32.750 \\
\hline 8 & Harga Bahan Baku(Rp/kg) & f & 650 \\
\hline 9 & Sumbangan input lain(Rp/kg) & $\mathrm{g}$ & $1.210,1$ \\
\hline 10 & Nilai Produk(Rp/kg) & $m x d=k$ & $4.732,9$ \\
\hline \multirow[t]{2}{*}{11} & a. Nilai Tambah(Rp/kg) & $k-f-g=1$ & $2.872,8$ \\
\hline & b. Rasio Nilai Tambah (\%) & $(1 / k) \%=h \%$ & 0,61 \\
\hline \multirow[t]{2}{*}{12} & a. Imbalan Tenaga Kerja $(\mathrm{Rp} / \mathrm{kg})$ & $p=n x e$ & 370,63 \\
\hline & b. Bagian Tenaga Kerja (\%) & $(p / l) \%=q \%$ & 0,13 \\
\hline \multirow[t]{2}{*}{13} & a. Keuntungan & $r=l-p$ & $2.502,14$ \\
\hline & b. Tingkat Keuntungan (\%) & $(r / l) \%=0 \%$ & 0,87 \\
\hline
\end{tabular}

Sumber : Hasil Olahan Data Primer, 2010. 


\section{DAFTAR PUSTAKA}

Andi Efendi, 2007. Nilai Tambah Pisang Embuk Dan Distribusinya Studi Kasus Desa Burno Kecamatan Senduro Kabupaten Lumajang. Jurusan Agribisnis Fakultas Pertanian Universitas Muhammadiyah Malang.

Estiningtyas Budiasih, 2003. Analisis Nilai Tambah Agroindustri Sirup Markisa Studi Kasus Di Kopermas Kecamatan Rembang Kabupaten Rembang. Jurusan Agribisnis Fakultas Pertanian Universitas Muhammadiyah Malang.

Lia Anggraini, 2004. Analisis Biaya Dan Pendapatan Industri Rumah Tangga Jobong ( Studi Kasus Kelurahan Sukodono Kecamatan Gresik Kabupaten Gresik). Jurusan Agribisnis Fakultas Pertanian Universitas Muhammadiyah Malang.

Majalah Pengusaha, 2008. Peluang Usaha Dan Solusinya - Potensi Besar Singkong. Edisi 89. Jakarta.

Ningsih, Gumoyo Mumpuni, 2001. Analisis Nilai Tambah Agroindustri Jenang Beras ( Kasus Di Desa Nogolaten Kecamatan Jetis Kabupaten Ponorogo). Universitas Muhammadiyah Malang.

Widyastuti, Dyah Erni dkk, 1999. Kajian Usahatani Dan Nilai Tambah Agroindustri Garut ( Maranta Arundinacea L) Dalam Rangka Penyediaan Produk Subtitusi Tepung Terigu Di Jawa Timur. Universitas Muhammadiyah Malang.

www.wikipedia Bahasa Indonesia, Ensiklopedia Bebas - Singkong. 